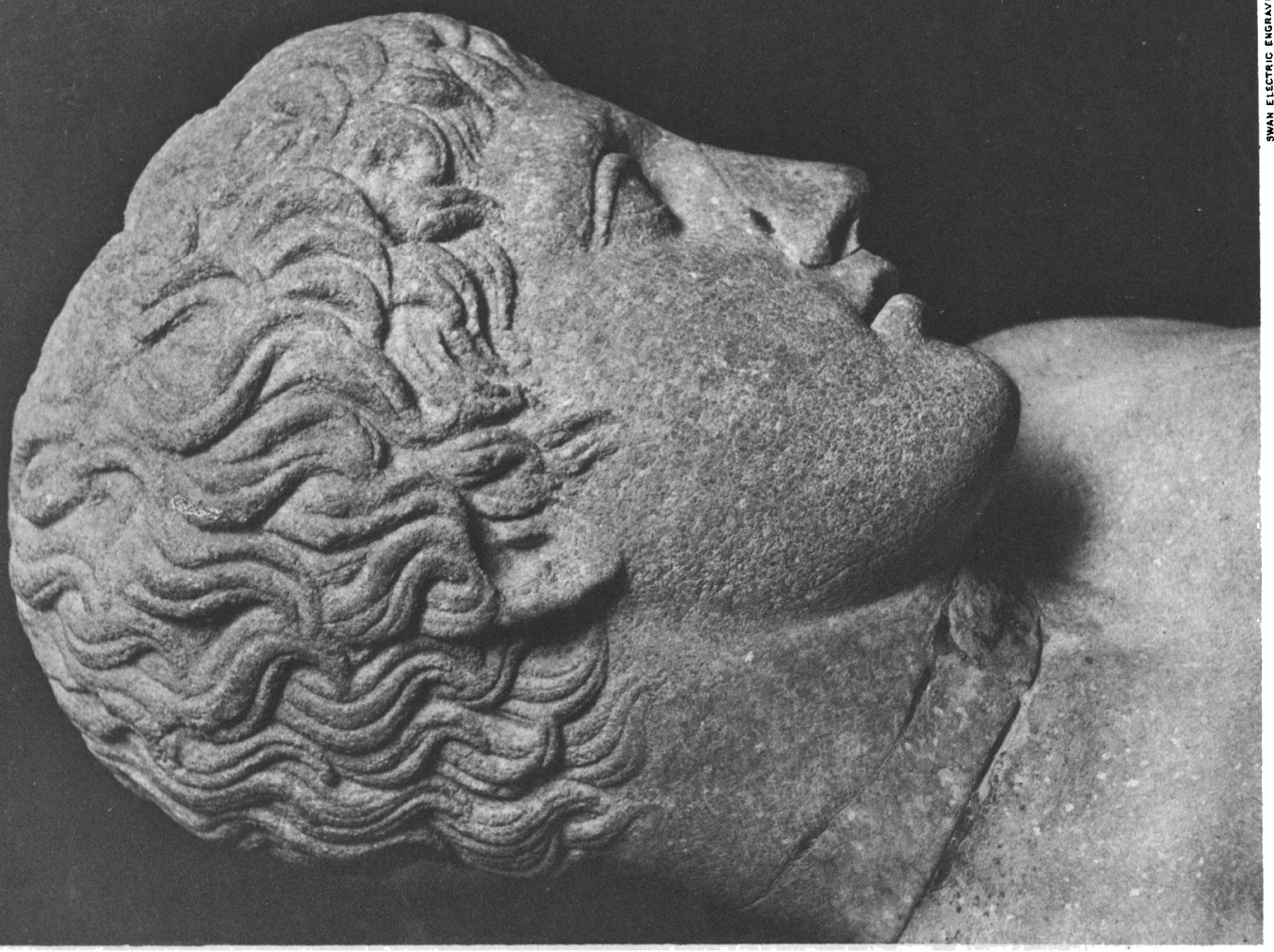




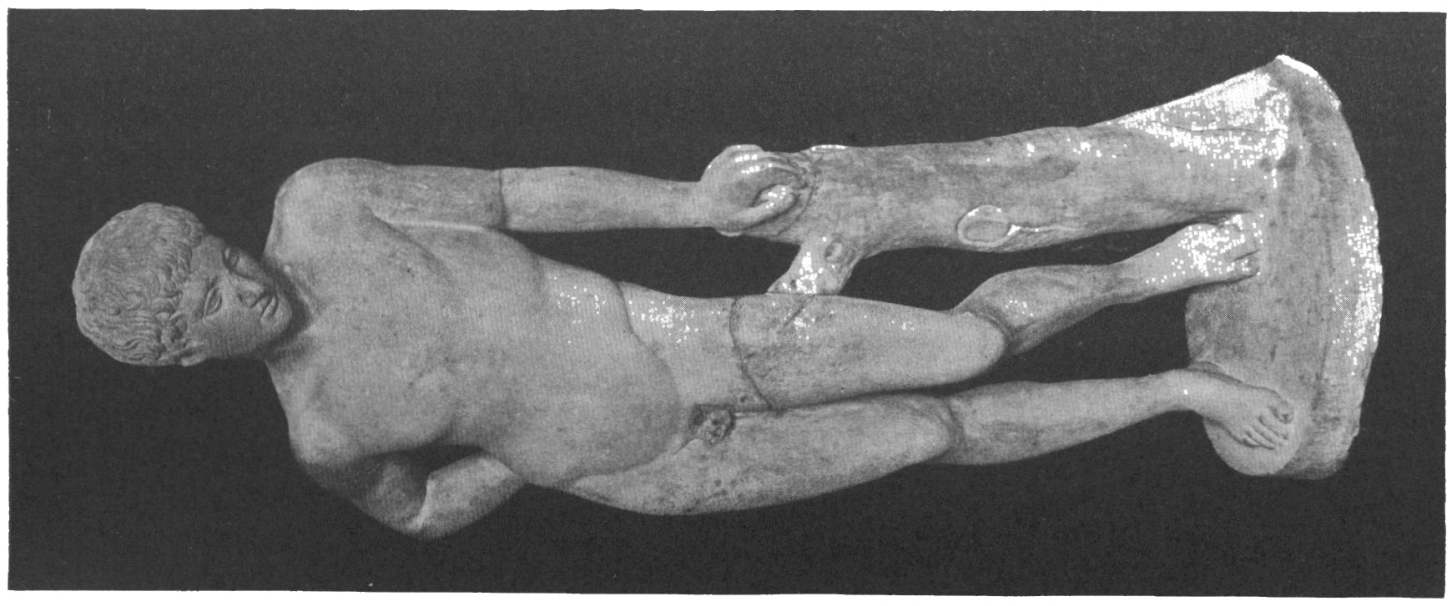

is

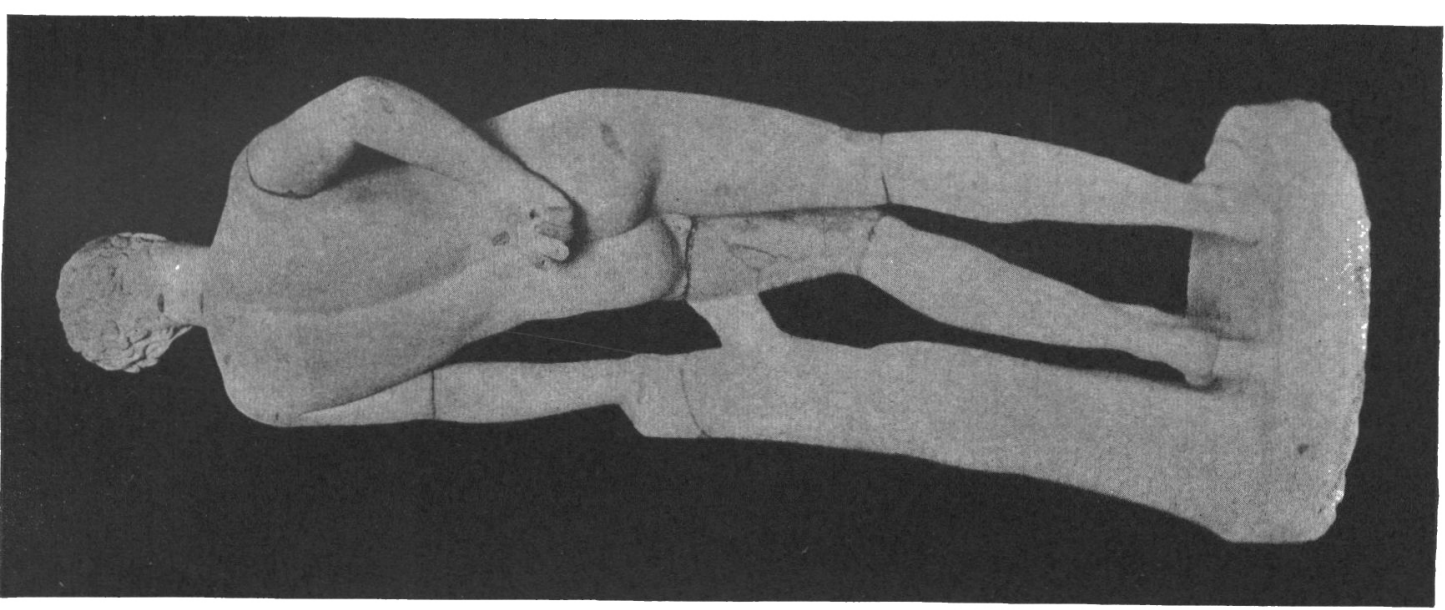

똥

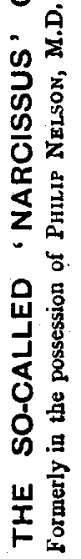

岁

岁

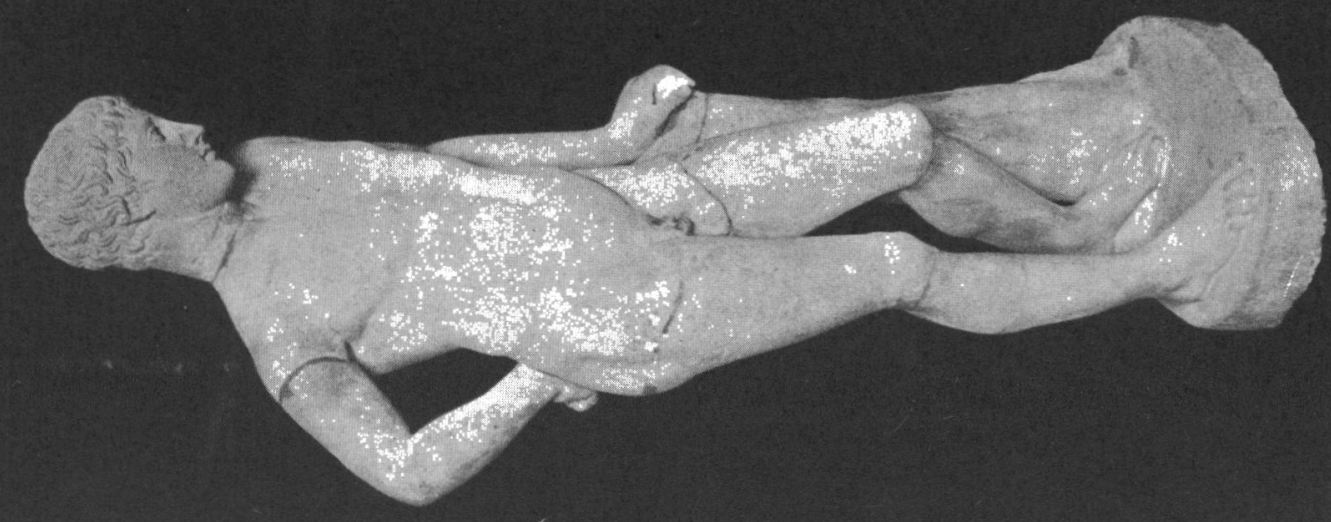




\title{
STATUE OF A BOY LEANING ON A PILLAR.
}

\author{
[Plates I., II.]
}

THIs statue, which was in the possession of Dr. Philip Nelson of Liverpool, has recently become the property of the Bavarian 'Verein der Kunstfreunde' who allow the charming work to be exhibited on loan in the Munich Glyptothek.1

That the original, of which this statue is a copy, was famous and popular in antiquity is amply proved by the large number of extant replicas. The present example brings up to twenty the number of authenticated replicas given in the English edition of Furtwängler's 'Masterpieces' (p. 272, note 4) and the list could doubtless easily be increased if the eleven replicas in Rome (Matz-Duhn, Antike Bildwerke in Rom, vol. i. pp. 275-278) and the thirtyseven replicas enumerated by M. Salomon Reinach in his Repertoire de la Statuaire (Index, s.v. ' Narcissus') could be thoroughly examined and sifted. This is a task which I had proposed to myself in view of this paper, but which I have as yet been unable to carry out.

It is strange that no other instance of the type appears to exist in the rich English private collections, if we except the entirely restored torso, with the movements reversed, at Rossie Priory (Michaelis, Ancient Marbles in Great Britain, Rossie, No. 1) and the more than doubtful example at Holkham (Michaelis, Holkham 20, Reinach, Repertoire i. p. 180, 1) which has been turned into a 'Meleager.'

The publication of this statue was courteously uffered to me by the English owner in May of last year, before it passed to Munich. The editors, however, having prepared and lettered the plates for this number of their Journal, cannot well withdraw or postpone them. At present, therefore, I must be content to contribute a few words of description based upon the photographs, and upon observations kindly sent to me by the former owner, though I shall probably seek to resume the subject when I have examined the replicas outside the list in the 'Masterpieces.' I may add that this 'Boy' is only one item among a number of notes upon 'inedited works of

1 See a note on p. 296 of the Burlington Magazine for January 1906. H.S.-VOL. XXVI. 
antique art in English private collections,' the publication of which, however, other more urgent work has obliged me to postpone.

The restorations in our statue are very numerous and apparently not altogether happy. The nose, the left arm from the elbow, the legs from the knees, the tree trunk and the plinth are all modern. Moreover, the left arm is wrongly restored with the hand turned outward, towards the spectator, instead of backward with the palm resting on the supporting pillar. The correct movement and pose of this arm are well known from the beautiful replica found in the Nile Delta and purchased by the Louvre in 1894 (published by E. Michon in Monuments Piot, i. Pl. xvii.; text pp. 115-128). The head of our Nelson-Munich replica has been badly replaced, owing to the markedly clumsy restoration of the neck: the pose should be corrected, again by comparison with the Louvre example. But in itself the head, save for the restored nose, seems to reproduce with simplicity and sincerity the lines of a distinguished original of the latter half of the fifth century B.C. Furtwängler, who first brought the type into prominence in his 'Masterpieces' (pp. 272-275 ; cf. also his article in Bull. d. I. 1877, p. 158), places the lost original within a cycle of Argive creations, immediately influenced by Polykleitos. In fact from the pose of the feet he links the statue to a group of works more or less closely connected with the 'Pythokles,' the basis of which is extant at Olympia. Furtwängler shews, however, that the type, though Polykleitan in its essence, is not uninfluenced by Attic models (ib. p. 274). On the other hand, M. Michon, to whom we owe an excellent critical notice of the Louvre statue, inclines rather to the theory of an Attic origin. The view taken by Dr. Amelung in his descriptions of the replicas in the Colonna Gallery (Arndt-Amelung-Bruckmann, Einzelaufnahmen, No. 1139) and in the Museo Chiaramonti (Amelung, Skulpturen des Vaticanischen Museums, vol. i. No. 536, Plate 70) is that the type is the direct product of combined Attic and Argive influence with preponderance of the Attic. ${ }^{2}$

In the Louvre, and apparently also in the Munich figures, the broad frontal construction is especially interesting, and proves at once the comparatively early period of the original. The forms are soft, yet the absence of any roundness of modelling is conspicuous. This flatness of the planes-always a concomitant of frontal construction-gives effect to the beautiful, curving silhouette. The design is severely self-contained, the silhouette finding its starting and meeting points at what affords the key, so to speak, to the whole, composition, the supporting palm of the left hand. The chiastic construction is peculiarly emphasized, the weight on the left hand being balanced by the weight on the right leg, and the bend of the right elbow by the bend of the left knee.

The marked inclination of the head, the melancholy satiety of the expression, the weariness of body suggested by the pose of the left hand, all seem carefully thought out in order to express some psychological state

2 Until I have examined more replicas, I do not feel competent on Dr. Amelung's theory of

two versions of the 'Narcissus,' the one more Polykleitan, the other more Attic in character. 
peculiar to the subject represented. As M. Michon subtly remarks (Mon. Piot, i. p. 125) 'son laisser aller va au delà du simple repos physique et s'étend du corps à l'esprit.' In spite too of the sweetness of the forms of the face, there is yet a sombreness of expression to which we are unaccustomed before the Roman period and the portraits of Antinous. ${ }^{3}$ This attempt to attain to spiritual individuality gives the statue an almost unique place among the more generalized creations of the period to which it belongs technically as well as structurally, and efforts to discover the name of the being represented have been plentiful, although, owing to lack of corroborative evidence, none brings definite conviction. Furtwängler disposes of the name of Narcissus by which the type has long been known, and of his own earlier interpretation of Hyacinthus, and at the same time he wishes to substitute that of Adonis. The present writer inclines to the theory, already many times put forward and rejected, that the figure has a sepulchral intention, that it commemorates some young athlete snatched away perhaps in the moment of success and victory. The so-called 'Adonis' has been brought by Furtwängler into relation with the earlier versions of the 'wearied Herakles' leaning forward on his club; nor must it be forgotten that this type of Herakles was shewn by Mr. A. S. Murray to have been transformed into a sepulchral figure in the beautiful Athenian' stele acquired a few years ago for the British Museum (J.H.S. xxii. 1902, Plate I.).

The dimensions of the statue, which is about two-thirds life size, are, I am informed, identical with those of the Louvre replica (Michon, p. 116), the total height being $1 \cdot 125$ metre.

\section{EugÉNIE STrong.}

\footnotetext{
3 The melancholy of the expression has been more than once compared with that of the 'Wounded Amazon' of Polykleitos. But if
}

the two works are consillered side by side, a deeper and more individual emotion will be felt to pervade the 'Narcissus ' than the 'Amazon.' 